\title{
Outcomes for high risk New Zealand newborn infants in 1998-1999: a population based, national study
}

\author{
A E Cust, B A Darlow, D A Donoghue, on behalf of the Australian and New Zealand \\ Neonatal Network (ANZNN)
}

See end of article for authors' affiliations

Correspondence to: Ms Donoghue, ANZNN, Building D02, University of Sydney, Sydney, NSW,

Australia, 2006:

ANZNN@

perinatal.usyd.edu.au

Accepted 11 July 2002

\begin{abstract}
Objective: To determine short term morbidity and mortality outcomes, provision of care, and treatments for a national cohort of high risk infants born in 1998-1999 and admitted to New Zealand neonatal intensive care units (NICUs).

Setting: All level III (six) and level II (13) NICUs in New Zealand.

Methods: Prospective audit by the Australian and New Zealand Neonatal Network (ANZNN) of all infants defined as "high risk" (born at $<32$ weeks gestation or $<1500 \mathrm{~g}$ birth weight, or received assisted ventilation for four hours or more, or had major surgery). Data were collected from birth until discharge home or death.

Results: There were 3368 high risk infants (3.0\% of all live births), comprising $1241(37 \%)<32$ weeks gestation, $1084(32 \%)<1500 \mathrm{~g}, 3156(94 \%)$ who received assisted ventilation, and $243(7 \%)$ who received major surgery (categories overlap). Most infants (87\%) received some care in tertiary hospitals, and $13 \%$ were cared for entirely in non-tertiary hospitals. Survival was $91 \%$ for infants $<32$ weeks gestation, $97 \%$ for infants $\geqslant 32$ weeks gestation who received assisted ventilation, and $92 \%$ for infants $\geqslant 32$ weeks gestation who had major surgery. The proportion of very preterm infants who survived free of early major morbidity was $11 \%, 28 \%, 53 \%, 81 \%$, and $90 \%$ for infants born at $<24$, 24-25, 26-27, 28-29, and 30-31 weeks gestation respectively.

Conclusions: These unique population based national data provide contemporary information on the care and early morbidity and mortality outcomes for all high risk infants, whether cared for in hospitals with level III or level II NICUs.
\end{abstract}

$\mathrm{P}$ opulation based studies on the provision of care and outcomes of high risk infants are essential for the evaluation of perinatal care services and neonatal intensive care programmes. They minimise selection bias and thus provide a more accurate view of the population than institution based studies. ${ }^{1}$ Literature reporting outcomes of infants admitted to neonatal intensive care units (NICUs) tend to focus on those most preterm or with the lowest birth weights, of which few are population based. ${ }^{2-8}$ Furthermore, many studies report only those infants admitted to NICUs with full facilities to care for critically ill infants (level III NICUs) ${ }^{9}$ or only inborn infants, ${ }^{10}$ reflecting a different case mix from the infants receiving intensive care in hospitals with special care facilities to manage mildly ill infants (level II NICUs).

In New Zealand, the short and long term outcomes of the national population of very low birthweight infants $(<1500$ g) and those $<28$ weeks gestation, who were live born in 1986 and admitted to a neonatal unit, have been reported as part of a prospective study of retinopathy of prematurity (ROP). ${ }^{11-16}$ However, there are no published New Zealand data and few international population based studies ${ }^{9}{ }^{17}$ reporting outcomes for a broader range of high risk infants, such as those who receive assisted ventilation or have major surgery. There are also no contemporary New Zealand data on outcomes for very preterm infants $(<32$ weeks gestation) reported by gestational age, which is most useful for facilitating decision making in obstetrics. Recent data are the most informative and reflect current practices in neonatal care, as the last decade has seen the introduction of new treatments and evolving modes of ventilatory support.

Neonatal networks play an important role in evaluating neonatal intensive care practices and outcomes and assisting with quality improvement. ${ }^{18} 19$ The Australian and New Zealand Neonatal Network (ANZNN) conducts a prospective audit of high risk infants admitted to neonatal units. Since 1995, all 29 hospitals with level III NICUs in Australia and New Zealand have formed part of this network. New Zealand has a population of 3.8 million people, with an infant death rate of 5.6 per $1000,{ }^{20}$ and there are six regional hospitals with level III NICUs.

The aim of this study was to determine the current population based morbidity and mortality outcomes until discharge home, and the provision of care and treatments for all high risk infants born in 1998-1999 and admitted to New Zealand NICUs. To meet the study objectives, the ANZNN expanded to include all 13 hospitals with level II NICUs in New Zealand, ensuring unique, comprehensive data for the entire New Zealand population of high risk infants born in 1998-1999 and admitted to tertiary or non-tertiary hospitals.

Data are reported for the following high risk groups: infants of less than 32 weeks gestation; infants born at 32 weeks or more who received assisted ventilation; infants born at 32 weeks or more who received major surgery. Data on infants of birth weight less than $1500 \mathrm{~g}$ are presented in the following paper. $^{21}$

\section{STUDY POPULATION AND METHODS}

The study population comprised all infants who were born alive between 1 January 1998 and 31 December 1999, admitted to a

Abbreviations: NICU, neonatal intensive care unit; ANZNN, Australian and New Zealand Neonatal Network; IPPV, intermittent positive pressure ventilation; CPAP, continuous positive airways pressure; GA, gestation; $C L D$, chronic lung disease; NEC, necrotising enterocolitis; ROP, retinopathy of prematurity; IVH, intraventricular haemorrhage; HMD, hyaline membrane disease. 
hospital with a level II or level III NICU in New Zealand, and met the ANZNN's "high risk" criteria: born at less than 32 completed weeks gestation, or born weighing less than 1500 g (very low birthweight), or received assisted ventilation (intermittent positive pressure ventilation (IPPV) and/or continuous positive airways pressure (CPAP)) for four or more consecutive hours, or had major surgery (defined as the opening of a body cavity).

Infants were only included if admitted to a NICU during their first hospital stay and within 28 days of birth. Infants who died in the labour ward were excluded.

All hospitals with level III NICUs (herein referred to as "level III hospitals" or "tertiary hospitals"; $\mathrm{n}=6$ ) and all hospitals with level II NICUs (herein referred to as "level II hospitals"; $n=13$ ) in New Zealand participated in the study, as part of the ANZNN's audit. All hospitals that cared for sick newborn infants and all infants born in New Zealand who met the ANZNN high risk criteria were included in the study.

New Zealand has a regionalised system of perinatal and neonatal care, with tertiary hospitals located in the major cities and coordinating the care of most high risk pregnancies and critically ill infants within their geographic region. Neonatal intensive care and special care is fully state funded, with the funding pattern reflecting the regionalised nature of the service. Level III NICUs provide full intensive care facilities including long term assisted ventilation and neonatal surgery. Level II hospitals, which are all related to the regional level III hospital, care for infants over 32 weeks gestation or $1500 \mathrm{~g}$ birth weight, and requiring short term ventilatory assistance only, although four level II+ hospitals also provide care for some infants over 28 weeks or $1000 \mathrm{~g}$ birth weight and do provide continuing nasal CPAP but not endotracheal ventilation. Level I hospitals are local hospitals with no facilities for sick newborns.

Data were collected prospectively by staff at the participating neonatal units, either on ANZNN forms or by incorporating the necessary variables into their local database. There were 68 data variables, which related to maternal and pregnancy risk factors, birth, treatment, and mortality and morbidity outcomes, until death or discharge home. Transfer details were recorded and date of discharge home as well as other relevant outcome information was sought from the transfer hospitals. The $30(0.89 \%)$ infants whose discharge date was not available from the transfer hospital were assumed to have survived to go home. Missing or anomalous data were identified and queried at entry into the ANZNN database. Quality checks were performed to identify outliers, duplicates, abnormal dates, or other anomalous data, and consistency of information. Confidentiality guidelines, as outlined in the reports, were strictly adhered to and no patient identifying information was collected.

Gestational age (GA) was reported in completed weeks of gestation, from the first day of the last menstrual period, or by prenatal and/or postnatal clinical assessment when accurate information on the last menstrual period was not available. Data are reported according to the four high risk criteria, in gestational age categories, with very low birthweight infants reported in detail in the following paper. $^{21}$ Very preterm infants were defined as 20-31 weeks GA, extremely preterm as $<28$ weeks GA, moderately preterm as 28-31 weeks GA, mildly preterm as $32-36$ weeks GA, and term as $37-44$ weeks GA. ${ }^{22}$

Definitions were developed by the members of the ANZNN and are reported in the ANZNN annual reports. ${ }^{23}{ }^{24}$ Major congenital malformations were coded according to the International Classification of Diseases, 9th revision. ${ }^{25}$ Infection was defined as a proven episode of bacterial, fungal, or viral systemic infection. ${ }^{26}$ Chronic lung disease (CLD) was defined as the need for respiratory support (oxygen, CPAP, or IPPV) at 36 weeks of corrected postmenstrual age for infants born at less than 32 weeks GA. A major neonatal morbidity was defined as having at least one of the following: CLD, definite necrotising enterocolitis (NEC), ${ }^{27}$ retinopathy of prematurity (ROP) stage 3 or $4,^{28}$ intraventricular haemorrhage (IVH) grade 3 or $4,{ }^{29}$ periventricular leucomalacia, porencephalic cyst, or hydrocephalus. One "day" of assisted ventilation was defined as four or more consecutive hours of assisted ventilation in any 24 hour period.

To improve the generalisability of the outcomes for very preterm infants, the ANZNN data were compared with New Zealand national statistics ${ }^{30}$ for the calendar year 1999 (data were not available for 1998) to determine the number of liveborn and stillborn infants not included in the cohort. For infants <32 weeks GA, values where the birthweight category was more than 4 standard deviations outside the mean for the infant's gestation and $\operatorname{sex}^{31}$ were excluded $(\mathrm{n}=24)$, these being assumed to be data errors. Registered live births were defined as those born showing some evidence of life, irrespective of gestational age. Registered stillbirths were defined as babies born without signs of life who either weighed $400 \mathrm{~g}$ or more or were born after 20 weeks GA.

Infants admitted directly to either Starship Children's Hospital or Greenlane Hospital in Auckland for paediatric or cardiac intensive care were not eligible for this study if they were not admitted to any level II or level III NICUs. Infants cared for exclusively in non-tertiary hospitals for the first 28 days were registered to that level II hospital. Infants admitted to or transferred to a level III hospital within 28 days of birth were registered to the first level III hospital in which they remained for four or more hours.

Statistical analyses were performed using SAS version 8 . The Mantel-Haenszel test for trend $\left(\chi_{1}^{2}\right)$ was used to analyse trends in proportions for dichotomous variables. Statistical significance was defined at the $\mathrm{p}<0.05$ level.

\section{RESULTS}

\section{Number of high risk infants}

During 1998-1999, there were 3368 infants in New Zealand who met the ANZNN's definition of high risk. This cohort represented $3.00 \%$ of the 112402 New Zealand live births for the same years. ${ }^{20}$ Grouped according to the four high risk registration criteria, there were 1241 (37\%) infants born at $<32$ weeks GA, 1084 (32\%) at < 1500 g, 3156 (94\%) who received assisted ventilation for four hours or more, and 243 $(7 \%)$ infants who received major surgery (categories overlap). The number of infants registered to each NICU during the two year period ranged from 157 to 954 for level III hospitals and 0 to 86 for level II hospitals.

\section{Characteristics of the cohort}

Table 1 shows the characteristics of the cohort of all 3368 high risk infants.

\section{Antenatal characteristics}

The majority $(64 \%)$ of the mothers were caucasian, with a further $21 \%$ identified as Maori and $9 \%$ as Pacific Islander. For infants born at $<37$ weeks GA, the predominant obstetric problem that led to their preterm birth was preterm labor (33\%). Other problems leading to preterm birth were hypertension in pregnancy $(17 \%)$, preterm, prelabour rupture of membranes (14\%), and antepartum haemorrhage (11\%). Many $(45 \%)$ term births had no identifiable antenatal problems, and $22 \%$ had fetal distress as their main antenatal problem.

The mothers of $63 \%$ of infants were booked at the hospital where the infant was registered for the audit, comprising $51 \%$ booked at a level III hospital and 12\% booked at a level II hospital. Of infants who were registered to a level II hospital for their care, $90 \%$ of mothers were booked. Extremely preterm infants had the highest proportion of in utero transfers $(41 \%)$ to their registration hospital and term infants had the highest proportion transferred after birth (33\%). The majority (59\%) 


\begin{tabular}{|c|c|c|c|c|c|}
\hline Characteristics & $\begin{array}{l}21-27 \\
(n=397)\end{array}$ & $\begin{array}{l}28-31 \\
(n=844)\end{array}$ & $\begin{array}{l}32-36 \\
(n=1244)\end{array}$ & $\begin{array}{l}37-44 \\
(n=883)\end{array}$ & $\begin{array}{l}\text { All } \\
(n=3368)\end{array}$ \\
\hline \multicolumn{6}{|l|}{ Maternal ethnicity } \\
\hline Maori & $91(23)$ & $183(22)$ & 226 (19) & $184(21)$ & $684(21)$ \\
\hline Pacific Islander & $39(10)$ & $62(7)$ & $86(7)$ & 111 (13) & $298(9)$ \\
\hline Caucasian & $241(61)$ & $533(64)$ & $844(69)$ & $511(60)$ & $2129(64)$ \\
\hline Asian & $24(6)$ & $47(6)$ & $56(5)$ & $36(4)$ & $163(5)$ \\
\hline \multicolumn{6}{|l|}{ Source of referral to hospital } \\
\hline Booked at hospital & $176(48)$ & $453(62)$ & 750 (71) & $491(62)$ & $1870(63)$ \\
\hline In utero transport & $149(41)$ & $229(31)$ & $189(18)$ & $31(4)$ & $598(20)$ \\
\hline Ex utero transport & 35 (10) & $45(6)$ & $109(10)$ & 257 (33) & 446 (15) \\
\hline Other & $6(2)$ & 8 (1) & $9(1)$ & 10 (1) & $33(1)$ \\
\hline \multicolumn{6}{|l|}{ Place of birth } \\
\hline Level III hospital & $358(90)$ & $714(85)$ & $933(75)$ & $478(55)$ & $2483(74)$ \\
\hline Level II hospital & $30(8)$ & 105 (12) & $255(21)$ & $219(25)$ & 609 (18) \\
\hline Infants from multiple birth & $93(23)$ & $257(30)$ & $276(22)$ & $18(2)$ & 644 (19) \\
\hline Male sex & $221(56)$ & 447 (53) & $732(59)$ & $552(63)$ & $1952(58)$ \\
\hline Intubated at resuscitation & 295 (74) & $216(26)$ & $143(12)$ & $172(20)$ & $826(25)$ \\
\hline Apgar score $<4$ at $5 \mathrm{~min}$ & $25(6)$ & 10 (1) & 17 (1) & $47(5)$ & $99(3)$ \\
\hline Major congenital malformation & $14(4)$ & $48(6)$ & $83(7)$ & 163 (19) & $308(9)$ \\
\hline
\end{tabular}

Values are numbers with percentages in parentheses.

of infants transferred ex utero were accompanied by a retrieval team with specialist neonatal training.

\section{Place of birth and place of care}

Overall, 2483 (74\%) infants in the cohort were born in a level III hospital, decreasing from $90 \%$ at $21-27$ weeks gestation to $55 \%$ at term. Another 609 (18\%) infants were born in level II hospitals, and $188(6 \%)$ were born in a level I hospital. Of infants born in a level II hospital, 188 (31\%) were transferred to a level III hospital during their hospital stay, the highest proportion at $<28$ weeks GA $(77 \%)$, followed by term infants (37\%), infants 28-31 weeks GA (27\%), and infants 32-36 weeks GA $(22 \%)$. Most $(80 \%)$ of these transfers occurred within one day of birth.

There were 2917 (87\%) high risk infants who were admitted to a level III NICU within 28 days of birth, including $98 \%$ of infants $<28$ weeks GA and $90 \%$ of infants $28-31$ weeks GA, and their care was registered to the level III hospital. Level II hospitals cared entirely for the remaining 451 (13\%) high risk infants, including $7 \%$ at $<32$ weeks. Of infants registered to level III hospitals, 688 (24\%) were transferred to a nontertiary hospital before going home, the majority $(\mathrm{n}=490$, $71 \%$ ) going to a level II hospital. Very preterm infants accounted for $56 \%$ of those back transferred to level II hospitals, at a median of 32.4 weeks equivalent gestation, with $11 \%$ continuing to receive assisted ventilation after transfer. Overall, $996(30 \%)$ of all infants in the cohort were admitted to a level II hospital for care at some time before discharge home. Some infants were transported between level III hospitals $(\mathrm{n}=100,3 \%)$, or to Greenlane or Starship Hospitals for specialist care or surgery $(n=88,3 \%)$. Altogether, $44 \%$ of infants were involved in at least one episode of antenatal or neonatal transport.

\section{Infant characteristics and condition at birth}

Most infants were male (58\%), particularly term infants $(63 \%)$, and $19 \%$ of infants were from a multiple birth. At birth, $25 \%$ of infants received intubation at resuscitation, and 3\% had an Apgar score of less than 4 at five minutes; however, these proportions were highest for extremely preterm infants ( $74 \%$ and $6 \%$ respectively). Some $19 \%$ of term infants in the cohort had a major congenital malformation that was diagnosed before discharge.

\section{Very preterm infants ( $<\mathbf{3 2}$ weeks gestation)}

Table 2 shows the treatments used for very preterm infants and their morbidity and mortality outcomes.

\section{Treatments}

Antenatal corticosteroids were given to the mothers of $83 \%$ of very preterm infants and $79 \%$ of infants $<34$ weeks GA, with $74 \%$ and $73 \%$ respectively receiving the recommended completed course of two doses within seven days of birth. Exogenous surfactant was given to $90 \%$ of very preterm infants with hyaline membrane disease (HMD) who received IPPV.

\section{Morbidity and mortality}

Screening for ROP was reported for $69 \%$ of very preterm infants, but increased to over $90 \%$ for infants $<28$ weeks GA. However, the New Zealand recommendations during this period were that screening should be conducted in all infants $<31$ weeks GA or $<1250 \mathrm{~g}^{32}$ and according to this criterion, $76 \%$ of eligible infants were reported to be "examined". For the group for which screening was recommended, $18 \%$ of examined infants developed stage 1 or 2 ROP, and 3\% developed stage 3 or 4 ROP, rates similar to those reported for all infants $<32$ weeks GA (table 2). Treatment for ROP was given to 11 infants ( $1.4 \%$ of infants $<32$ weeks who survived and were examined for ROP), all of whom were $<28$ weeks GA.

Overall, 1116 (90\%) very preterm infants had an ultrasound or postmortem examination during the first 10 days of life to detect IVH. A quarter (24\%) of the infants who did not have an initial head ultrasound had died during the first 10 days. For the $638(57 \%)$ infants who had a late head ultrasound recorded more than 20 days after birth and were alive at discharge, a low incidence of cerebral abnormalities was detected (hydrocephalus $1.3 \%$, periventricular leucomalacia $1.6 \%$, porencephalic cysts $2.7 \%)$. A total of $72(6 \%)$ very preterm infants had major surgery, including $32(22 \%)$ infants at $24-25$ weeks GA.

Decreasing gestational age was significantly associated with increasing rates of morbidities, including infection, NEC, CLD, any stage of ROP, any grade of IVH, and decreasing survival $(\mathrm{p}<0.001)$. Infants $<24$ weeks GA had the lowest survival rate $(42 \%)$ and the lowest proportion of infants surviving free of early major morbidity (11\%). There were no survivors born at $<23$ weeks GA $(\mathrm{n}=3)$, nor born at both $<24$ weeks GA and $<500 \mathrm{~g}(\mathrm{n}=4)$. Overall, $1129(91.0 \%)$ very preterm infants survived to discharge home. Of the 112 infants who died, $76(68 \%)$ died within seven days, and 20 (18\%) deaths were directly attributable to a major congenital malformation. Excluding those with lethal congenital malformations, 92.5\% 
Table 2 Treatments and outcomes for very preterm infants $(<32$ weeks gestation) divided into gestational age groups (weeks)

\begin{tabular}{|c|c|c|c|c|c|c|}
\hline Treatments and outcomes & $<24(n=19)$ & $24-25(n=148)$ & $26-27(n=230)$ & $28-29(n=345)$ & $30-31(n=499)$ & All $<32(n=1241)$ \\
\hline Antenatal corticosteroids* & $9(69)$ & $97(82)$ & $145(82)$ & $221(82)$ & $319(84)$ & $791(83)$ \\
\hline Surfactant for HMD** & $10(83)$ & $102(89)$ & 139 (94) & 145 (93) & $94(81)$ & $490(90)$ \\
\hline Proven systemic infection & $7(37)$ & $79(53)$ & $96(43)$ & $84(24)$ & $59(12)$ & $325(26)$ \\
\hline Proven necrotising enterocolitis & $0(0)$ & $15(10)$ & $12(5)$ & $9(3)$ & $5(1)$ & $41(3)$ \\
\hline \multicolumn{7}{|l|}{ Respiratory morbidity } \\
\hline Received assisted ventilation & $19(100)$ & 147 (99) & $230(100)$ & $331(96)$ & $417(84)$ & $1144(94)$ \\
\hline Air leak requiring drainage & $3(16)$ & $16(11)$ & $14(6)$ & $17(5)$ & $15(3)$ & $65(5)$ \\
\hline Oxygen at 36 weeks PMA $†$ & $6(75)$ & $44(42)$ & $56(28)$ & $30(9)$ & $23(5)$ & $159(14)$ \\
\hline Resp support at 36 weeks PMA $†$ & $6(75)$ & 49 (47) & 61 (30) & $33(10)$ & $23(5)$ & $172(15)$ \\
\hline Home oxygen therapy $\ddagger$ & $4(50)$ & $25(24)$ & $31(15)$ & $8(2)$ & $5(1)$ & $73(6)$ \\
\hline \multicolumn{6}{|l|}{ ROP } & $11(4,37)$ \\
\hline Examined for ROP $\ddagger$ & $8(100)$ & 99 (93) & $181(91)$ & $252(77)$ & 235 (49) & 775 (69) \\
\hline Stage 1 or 21 & $3(38)$ & $38(38)$ & $43(24)$ & $37(15)$ & $6(3)$ & $127(16)$ \\
\hline Stage 3 or 4 & $2(25)$ & 13 (13) & $5(3)$ & $1(0)$ & $1(0)$ & $22(3)$ \\
\hline \multicolumn{7}{|l|}{ Intraventricular haemorrhage } \\
\hline Early ultrasound recorded & 15 (79) & $138(94)$ & $221(96)$ & $334(97)$ & $408(82)$ & $1116(90)$ \\
\hline Grade 1 or 2 & $2(13)$ & $20(14)$ & $40(18)$ & $39(12)$ & $27(7)$ & $128(11)$ \\
\hline Grade 3 or 4 & $5(33)$ & 21 (15) & $19(9)$ & $13(4)$ & $1(0)$ & $59(5)$ \\
\hline Late ultrasound recorded $\neq \mathbb{q}$ & $4(50)$ & $89(84)$ & $145(72)$ & $210(64)$ & 190 (39) & $638(57)$ \\
\hline Hydrocephalus & $0(0)$ & $5(6)$ & $0(0)$ & $3(1)$ & $0(0)$ & $8(1)$ \\
\hline Periventricular leucomalacia & $0(0)$ & $3(3)$ & $1(1)$ & $4(2)$ & $2(1)$ & $10(2)$ \\
\hline Porencephalic cysts & $0(0)$ & $2(2)$ & $8(6)$ & $4(2)$ & $3(2)$ & $17(3)$ \\
\hline Survived to discharge home & $8(42)$ & $106(72)$ & $201(87)$ & $328(95)$ & $486(97)$ & $1129(91)$ \\
\hline Survived free of major morbidity & $2(11)$ & $41(28)$ & $123(53)$ & 281 (81) & 451 (90) & $898(72)$ \\
\hline Length of stay (days) $\ddagger$ & $125(114,135)$ & $106(95,122)$ & $82(70,98)$ & $61(53,72)$ & $42(34,51)$ & $59(43,79)$ \\
\hline PMA at discharge home (weeks) $\ddagger$ & $40.8(39.2,42.2)$ & $39.7(38.4,41.5)$ & $38.3(36.9,40.1)$ & $37.4(36.1,38.4)$ & $36.4(35.6,37.7)$ & $37.3(36.0,39.0)$ \\
\hline \multicolumn{7}{|c|}{$\begin{array}{l}\text { Data are presented as number }(\%) \text { or as median }(25 \text { th, } 75 \text { th centiles). Outcomes of ROP examinations and head ultrasounds are presented as a percentage } \\
\text { of those examined. } \\
\text { *Excludes data for two neonatal intensive care units for which data were unavailable. } \\
\text { **For infants who received intermittent positive pressure ventilation for } \geqslant 4 \text { hours and had a respiratory diagnosis of HMD. } \\
\text { †Of infants surviving to } 36 \text { weeks PMA. } \\
\text { †Of infants who survived to go home. } \\
\text { §For infants who received assisted ventilation and survived to go home. } \\
\text { TLate head ultrasound defined as a head ultrasound recorded }>20 \text { days after birth. } \\
\text { HMD, Hyaline membrane disease; PMA, postmenstrual age; ROP, retinopathy of prematurity. }\end{array}$} \\
\hline
\end{tabular}

of very preterm infants survived. Overall, $20 \%$ of very preterm infants who were discharged home had a major neonatal morbidity, significantly decreasing from $75 \%$ at $<24$ weeks GA to $61 \%, 39 \%, 14 \%$ and $7 \%$ at $24-25,26-27,28-29$, and $30-31$ weeks GA respectively $\left(\chi_{1}^{2}=210.1, \mathrm{p}<0.001\right)$. The median postmenstrual age when discharged home decreased with increasing gestation at birth, and overall $83 \%$ of very preterm infants went home before their estimated date of birth.

\section{Live births and stillbirths not in ANZNN data}

In New Zealand in 1999, there were 222 registered births of $<24$ weeks GA, of which 158 (71\%) were stillborn, and 64 (29\%) were live born. Of those born alive, 11 (17\%) were admitted to an NICU and thus included in this study. Hence, in 1999, 3\% of all infants (including live born and stillborn) born at 20-23 weeks GA survived, and 9\% of all liveborn infants born at 20-23 weeks GA survived. In this study, $42 \%$ of the infants born in 1998-1999 at $<24$ weeks GA and admitted to a NICU survived. For infants born at 24-31 weeks GA, ANZNN reported an extra 18 infants compared with the national statistics. A further 82 infants were stillborn at 24-31 weeks GA ( $11 \%$ of all infants born at 24-31 weeks GA). Of infants born at 32 weeks GA, 57\% of liveborn infants were in the ANZNN cohort, with the percentage of infants in the cohort decreasing with increasing gestational age, to less than $1 \%$ for infants at $39-43$ weeks.

\section{Treatments and outcomes for infants $\geqslant 32$ weeks gestation who received assisted ventilation for four hours or more (excluding infants who had major surgery)}

The most common indications for respiratory support for these infants were non-specific respiratory distress (includes transient tachypnoea of the newborn, 38\%) and HMD (27\%) (table 3). The respiratory diagnoses were more heterogeneous with increasing gestational age. The predominant mode of assisted ventilation was CPAP only ( $\mathrm{n}=1415,76 \%)$. A combination of IPPV and CPAP was given to 289 (15\%) infants, and $168(9 \%)$ infants received IPPV only. Respiratory treatments administered to infants receiving IPPV included nitric oxide $(\mathrm{n}=78,17 \%)$, high frequency ventilation $(\mathrm{n}=22,5 \%)$, and extracorporeal membrane oxygenation $(n=5,1 \%)$. The main respiratory diagnoses for infants receiving nitric oxide were primary pulmonary hypertension $(\mathrm{n}=29)$ and meconium aspiration $(n=19)$, and for infants receiving high frequency ventilation the most common diagnosis was $\operatorname{HMD}(n=7$, $32 \%)$.

Supplemental oxygen was administered to $83 \%$ of infants. The median duration of assisted ventilation and oxygen treatment was relatively consistent at one to three days in all gestational age groups. A total of $1812(96.8 \%)$ infants in this high risk group survived to discharge home. Survival increased to $98.4 \%$ if infants with lethal congenital malformations ( $\mathrm{n}=30,50 \%$ of deaths) were excluded. The length of stay of survivors decreased from a median of 26 days at 32-33 weeks GA to seven days at term.

\section{Treatments and outcomes for infants $\geqslant 32$ weeks gestation who had major surgery}

There were 171 infants $\geqslant 32$ weeks gestation who received major surgery: 61 infants at 32-36 weeks GA and 110 term infants (table 4). There was a high proportion of infants with at least one major congenital malformation $(77 \%$ at $32-36$ weeks GA and $91 \%$ at term) in this high risk group, and this was their predominant reason for respiratory support. The survival rate to discharge home was $92.4 \%$ overall, including 
Table 3 Treatments and outcomes for infants $\geqslant 32$ weeks gestation who received assisted ventilation for $\geqslant 4$ hours

\begin{tabular}{|c|c|c|c|c|c|c|}
\hline Treatments and outcomes & $\begin{array}{l}32-33 \text { weeks } \\
(n=474)\end{array}$ & $\begin{array}{l}34-36 \text { weeks } \\
(n=626)\end{array}$ & $\begin{array}{l}37-38 \text { weeks } \\
(n=285)\end{array}$ & $\begin{array}{l}39-40 \text { weeks } \\
(n=313)\end{array}$ & $\begin{array}{l}>40 \text { weeks } \\
(n=174)\end{array}$ & $\begin{array}{l}\text { All } \geqslant 32 \\
(n=1872)\end{array}$ \\
\hline \multicolumn{7}{|l|}{ Reason for respiratory support } \\
\hline Hyaline membrane disease & $182(41)$ & 211 (37) & $51(20)$ & $14(5)$ & $10(6)$ & $468(27)$ \\
\hline Non-specific respiratory distress & $189(43)$ & $251(44)$ & 99 (38) & $89(30)$ & $37(22)$ & 665 (38) \\
\hline Pneumonia & $20(5)$ & 40 (7) & 35 (13) & $42(14)$ & $15(9)$ & $152(9)$ \\
\hline Newborn encephalopathy & $3(1)$ & $3(1)$ & $13(5)$ & $23(8)$ & $12(7)$ & $54(3)$ \\
\hline Pulmonary hypertension & $2(0)$ & $6(1)$ & $8(3)$ & $24(8)$ & $10(6)$ & $50(3)$ \\
\hline Meconium aspiration & 0 (0) & 1 (0) & $12(5)$ & 57 (19) & $54(32)$ & $124(7)$ \\
\hline Congenital malformation & $3(1)$ & $11(2)$ & $9(3)$ & $16(5)$ & $9(5)$ & $48(3)$ \\
\hline \multicolumn{7}{|l|}{ Mode of assisted ventilation } \\
\hline$I P P V+C P A P$ & $74(16)$ & $85(14)$ & $50(18)$ & $45(14)$ & $35(20)$ & $289(15)$ \\
\hline CPAP only & $375(79)$ & $507(81)$ & $205(72)$ & $212(68)$ & $116(67)$ & $1415(76)$ \\
\hline IPPV only & $25(5)$ & $34(5)$ & $30(11)$ & $56(18)$ & $23(13)$ & $168(9)$ \\
\hline Days of assisted ventilation* & $2(1,4)$ & $2(1,4)$ & $2(1,4)$ & $1(1,2)$ & $2(1,3)$ & $2(1,4)$ \\
\hline Days of supplemental oxygen * & $2(1,4)$ & $3(1,5)$ & $3(1,5)$ & $2(1,4)$ & $2(1,4)$ & $2(1,5)$ \\
\hline \multicolumn{7}{|l|}{ Respiratory treatments $\dagger$} \\
\hline High frequency ventilation & $5(5)$ & $4(3)$ & $1(1)$ & $7(7)$ & $5(9)$ & $22(5)$ \\
\hline Nitric oxide & $5(5)$ & $8(7)$ & $16(20)$ & $21(21)$ & $28(48)$ & 78 (17) \\
\hline Air leak requiring drainage & $14(3)$ & $31(5)$ & $22(9)$ & $14(5)$ & $9(5)$ & $90(5)$ \\
\hline Survived to discharge home & 470 (99) & 620 (99) & $273(96)$ & $284(91)$ & $165(95)$ & $1812(97)$ \\
\hline Length of stay (days) $\ddagger$ & $26(22,34)$ & $15(11,20)$ & $9(6,12)$ & $7(5,10)$ & $7(5,11.5)$ & $14(8,24)$ \\
\hline PMA at discharge home (weeks) $\ddagger$ & $36.3(35.6,37.3)$ & $37.1(36.6,37.7)$ & $38.9(38.3,39.4)$ & $40.9(40.4,41.1)$ & $42.4(41.9,43.0)$ & $37.9(36.6,40.1)$ \\
\hline
\end{tabular}

Data are presented as $\mathrm{n}(\%)$ or as median $(25$ th, 75 th centiles) and exclude infants $\geqslant 32$ weeks who had major surgery.

*For infants who received this treatment and survived to go home.

†For infants who received IPPV.

†For infants who survived to go home.

IPPV, Intermittent positive pressure ventilation; CPAP, continuous positive airways pressure; PMA, postmenstrual age.

$89 \%$ for mildly preterm infants and $95 \%$ for term infants. Nine $(69 \%)$ deaths were attributable to a major congenital malformation. Excluding those infants, $97.5 \%$ survived overall. The median length of stay was 41 days for infants 32-36 weeks GA and 19 days for term infants.

\section{DISCUSSION}

This paper describes the current care, treatments, and early morbidity and mortality outcomes for a national cohort of high risk infants born in 1998-1999 and admitted to neonatal

Table 4 Treatments and outcomes for infants $\geqslant 32$ weeks gestation who had major surgery

\begin{tabular}{|c|c|c|}
\hline Treatments and outcomes & $\begin{array}{l}32-36 \text { weeks } \\
(n=61)\end{array}$ & $\begin{array}{l}37-44 \text { weeks } \\
(n=110)\end{array}$ \\
\hline Major congenital malformation & 47 (77) & $100(91)$ \\
\hline $\begin{array}{l}\text { Antenatal diagnosis of fetal } \\
\text { malformation }\end{array}$ & 19 (46) & $29(43)$ \\
\hline Assisted ventilation for $\geqslant 4$ hours & $59(97)$ & $81(74)$ \\
\hline \multicolumn{3}{|l|}{ Mode of assisted ventilation* } \\
\hline$I P P V+C P A P$ & 23 (39) & $13(16)$ \\
\hline CPAP only & $3(5)$ & $6(7)$ \\
\hline IPPV only & $33(56)$ & 62 (77) \\
\hline \multicolumn{3}{|l|}{ Reason for respiratory support $\dagger$} \\
\hline Perisurgical support & $11(18)$ & $21(25)$ \\
\hline Congenital malformation & $22(37)$ & $40(48)$ \\
\hline Days of assisted ventilation $\ddagger$ & $4.5(3,9)$ & $3(1,4)$ \\
\hline Days of supplemental oxygen $\ddagger$ & $5(2,19)$ & $4(2,9)$ \\
\hline \multicolumn{3}{|l|}{ Respiratory treatments $\S$} \\
\hline High frequency ventilation & $8(14)$ & $3(4)$ \\
\hline Nitric oxide & $3(5)$ & $6(8)$ \\
\hline Survived to discharge home & 54 (89) & $104(95)$ \\
\hline Length of stay (days) $\mathbb{T}$ & $41(24,57)$ & $19(13,31.5)$ \\
\hline PMA at discharge home (weeks) & $\begin{array}{l}39.9 \\
(38.0,42.9)\end{array}$ & $\begin{array}{l}42.1 \\
(40.7,43.6)\end{array}$ \\
\hline
\end{tabular}

Data presented as $\mathrm{n}(\%)$ or as median (25th,75th centiles). *For infants who received assisted ventilation.

†For infants who received respiratory support (IPPV, CPAP or supplemental oxygen).

†For infants who received this treatment and survived to go home. $\S$ For infants who received IPPV.

IFor infants who survived to go home.

IPPV, Intermittent positive pressure ventilation; CPAP, continuous positive airways pressure; PMA, postmenstrual age. units in New Zealand. These data are unique, because they include infants admitted to all neonatal units in New Zealand, including tertiary and non-tertiary hospitals; they are population based and include a national cohort of high risk infants born during a two year period; and represent the spectrum of infants cared for in NICUs, as they include all infants who were very preterm, with very low birth weight, received assisted ventilation, or had major surgery. These data also provide insight into the regionalisation and management of neonatal services in New Zealand, as all level III and level II NICUs participated in this study.

There is a consensus that the birth and subsequent care of the extremely preterm infant should occur in regionalised, perinatal centres, with full facilities for neonatal intensive care, $^{23152233}$ and that antenatal transfer of the mother is the ideal mode of transport to the tertiary centre of care. ${ }^{34-36} \mathrm{New}$ Zealand has a well established system of regionalisation for neonatal intensive care. In this study, 93\% of extremely preterm infants were born in a level III hospital, achieved in part by their high rate $(41 \%)$ of in utero transfers. Only $3 \%$ of infants in the cohort were transported between level III hospitals, suggesting a suitable allocation of intensive care beds and resources during the study period.

However, there are few studies on the most appropriate place of birth for high risk infants at more mature gestations. Berg et $a l^{37}$ reported that for women who gave birth to infants weighing $2500 \mathrm{~g}$ or more and who developed a complication of labor, neonatal mortality at level I hospitals was increased compared with higher level hospitals, regardless of their prepartum risk status. They suggest referral of high risk women to level II or III hospitals for term delivery. However, in the New Zealand cohort, $45 \%$ of the mothers of term infants had no identifiable antenatal problems, and this may explain the high rate $(33 \%)$ of transport after birth for term infants.

Level III hospitals provided most of the care for this high risk cohort, but the level II hospitals played an integral role in that care. They stabilised infants before transport when necessary, cared entirely for $13 \%$ of all high risk infants, and provided continuing care for another $17 \%$ of infants once discharged from level III hospitals, particularly those born very preterm. This is an efficient means of conserving resources and reducing pressure on the level III hospitals. Furthermore, 
level II hospitals are often geographically isolated from the larger cities where the level III hospitals are located. The social, psychological, and economic impact on the family of antenatal and neonatal transfers to tertiary hospitals is an important yet understudied aspect of neonatal care. The inclusion of level II hospitals in existing neonatal networks is feasible and also ensures the completeness of data with regard to further treatment, eye examinations, and head ultrasounds on back transfer.

However, it is important to ensure that there is appropriate follow up of very preterm infants after back transfer, and our data suggest that performing eye examinations is one area where follow up could be improved. Not only is it imperative that infants have a retinal examination by someone experienced in indirect ophthalmoscopy, according to the national guidelines, ${ }^{32}$ but this should also be at the appropriate time to allow treatment should this be necessary.

One of the objectives of the ANZNN is to assess the uptake into clinical practice of evidence based recommendations such as those by the National Health and Medical Research Council of Australia $^{22}$ and the Cochrane database of systematic reviews. One such recommendation is that antenatal corticosteroids should be considered for all imminent births at $<34$ weeks $\mathrm{GA}^{22}$ in order to reduce mortality and the incidence of respiratory distress syndrome and IVH. $^{38}$ New Zealand scientists were the first to trial this treatment in $1970,^{39}$ and New Zealand continues to have one of the highest rates of antenatal corticosteroid administration $183 \%$ and $79 \%$ for infants $<32$ weeks GA and $<34$ weeks GA respectively, compared with $58 \%$ for infants $<34$ weeks GA in the Canadian NICU Network in 1996-1997, ${ }^{9} 71 \%$ for infants $501-1500 \mathrm{~g}$ in the NICHD Neonatal Network $1995-1996,{ }^{10}$ and $51 \%$ for infants $<32$ weeks GA in northern and eastern France ${ }^{40}$ ), as well as a high proportion (73\%) receiving the recommended course. Another recommended treatment is the administration of exogenous surfactant for preterm infants with HMD who receive IPPV. ${ }^{41}$ Some $90 \%$ of very preterm infants in this category received this treatment, which compares favourably with other studies. ${ }^{40}$

Overall, 91\% of infants $<32$ weeks GA in this high risk cohort survived to go home, increasing from $42 \%$ at $<24$ weeks GA to $97 \%$ at $30-31$ weeks. These survival rates are encouraging compared with other recent studies. A population based study in Trent, United Kingdom, of infants born at $<33$ weeks GA in 1997 and admitted to a neonatal unit, reported $88 \%$ survival to 36 weeks corrected premenstrual age. ${ }^{43}$ Also for the year 1997, eight level III NICUs in France reported 86\% survival for infants born at $<32$ weeks GA, despite a smaller proportion of infants $<25$ weeks GA ( $7 \%$ in the French study $v 13 \%$ in New Zealand). ${ }^{40}$

Reporting outcomes by gestational age rather than birth weight is more useful for decision making before birth, and is considered a better predictor of outcome for the extremely preterm infant. ${ }^{44}$ However, the ANZNN's audit criteria did not include liveborn infants who died in the labor ward, nor stillborn infants, which affects the generalisability and interpretation of these survival and morbidity rates, particularly for the extremely preterm infant. ${ }^{1}$ This limitation was overcome by comparing these data with national birth registrations for $1999,{ }^{30}$ which showed that the "true" survival rate for infants born at 20-23 weeks was $9 \%$ for liveborn infants, and 3\% including stillbirths. These survival rates suggest that the prognosis for infants at the limits of viability has not changed in the last decade. ${ }^{46}{ }^{47}$ The NICU admission rates in this study for liveborn infants at 20-23 weeks gestation (17\%) are lower than those reported in the United Kingdom and Ireland $(29 \%),{ }^{48}$ but the overall survival rate for these liveborn infants, irrespective of whether admitted to an NICU, was higher in this study ( $9 \% v 6 \%$ in the United Kingdom and Ireland).

For infants born at 24-31 weeks GA in 1999, an extra 18 infants were reported by the ANZNN compared with the national registration of births for that year. This difference is probably due to delays in the national registration of births during that year. ${ }^{20}$ However, although we cannot be certain of the actual number of labor ward deaths at 24-31 weeks GA, these data suggest that all of these liveborn infants were included in this study. National demographic data ${ }^{20}$ also show that the proportion of the infants' mothers who identified themselves as Maori (21\%) and Pacific Islander (9\%) in this study was comparable to the national maternal population, suggesting that these infants were not over-represented in this high risk cohort.

Numerous studies have shown that very preterm and very low birthweight infants with early neonatal morbidities have an increased risk of adverse long term neurological, functional, educational, and behavioural outcomes. ${ }^{513-16}$ 49-51 $^{\text {Over- }}$ all, $72 \%$ of all very preterm infants in this cohort survived to discharge and had no early major morbidity identified. These rates are similar to those reported by other NICU networks. The NICHD Neonatal Research Network reported 71\% survival without major morbidity (defined as grade 3 or 4 IVH, CLD, or NEC) for infants 501-1500 g. ${ }^{10}$ The Canadian NICU Network reported $69 \%$ survival without major morbidity for infants $<1500$ g, classifying major morbidity as CLD, NEC, grade 3 or 4 IVH, or stage 3 or 4 ROP.

There are few studies relating to the short and long term morbidities for high risk term infants, but there is some evidence that infants of birth weight $\geqslant 3500 \mathrm{~g}$ who are depressed at birth, or have a diagnosis of asphyxia, or have major congenital anomalies have a poor prognosis. ${ }^{17}{ }^{52}$ A recent population based study showed that mechanically ventilated term infants had more major disability $(17.2 \%)$ than control infants $(1.6 \%)$ at 3 years of age. ${ }^{53}$ A prospective study of 30 full term infants who had major neonatal surgery reported developmental delay at 1 year of age $\mathrm{e}^{54}$ and lower cognitive functioning at 3 years. ${ }^{55}$ Length of hospital stay ${ }^{54}$ and number of operation ${ }^{55}$ were strongly associated with poorer outcome. In New Zealand, infants of $\geqslant 32$ weeks GA who had major surgery stayed in hospital about two weeks longer than infants of similar gestations who received assisted ventilation but not surgery. Antenatal diagnosis of congenital malformations has contributed to the improved prognosis of infants undergoing neonatal surgery, ${ }^{56}$ and in this study, an antenatal diagnosis of a fetal malformation was made in nearly half of the infants receiving surgery.

There was an increasing use of CPAP over the two year period. Some $76 \%$ of infants of $\geqslant 32$ weeks GA who had assisted ventilation but not major surgery received CPAP only, compared with $6 \%$ for infants who had major surgery. A Northern Californian population reported a much larger proportion of infants at 32 weeks GA or more receiving IPPV only. ${ }^{42}$ However, the duration of assisted ventilation for both populations was similar, reporting a positively skewed duration of ventilation at $<32$ weeks GA, and a median of two days of assisted ventilation for infants born at $\geqslant 32$ weeks GA.

These population based national data will be beneficial to carers, parents, health service planners, health workers, and researchers. They will assist with quality improvement, highlighting areas where efficiency can be improved, allocating health resources, and in the planning of appropriate educational, community, and health services for these infants and their families. Data from the ANZNN serve as a basis for future research, including identifying variations in practice and outcomes after adjusting for risk, ${ }^{57}$ determining risk factors for morbidity and mortality, and in the planning of clinical trials.

\section{ACKNOWLEDGEMENTS}

We would like to acknowledge the dedicated efforts of the staff within the neonatal units in New Zealand who assisted with the data collection for this study. We would also like to thank Professor David Henderson-Smart for providing a critical review of the paper. We 
gratefully acknowledge Abbott Australasia, Abbott Laboratories New Zealand and the level III NICUs in Australia and New Zealand, who contributed to the sponsorship of the ANZNN.

The ANZNN Advisory Committee and Executive $\left({ }^{*}\right)$ members are as follows:

\section{New Zealand}

Christchurch Women's Hospital: Nicola Austin (from 1999), Helen Liley (until 1999). Christchurch School of Medicine: Brian Darlow*. Dunedin Hospital: Roland Broadbent. Gisborne Hospital: Graeme Lear. Hastings Hospital: Jenny Corban. Hutt Hospital: Robyn Shaw, Michael Hewson (1999). Middlemore Hospital: Alan de Klerk (until 1998), Lindsay Mildenhall (from 1999). National Women's Hospital: David Knight. Nelson Hospital: Richard Mackay (until 2001), Peter McIlroy (from 2001). Palmerston North Hospital: Jeff Brown. Rotorua Hospital: Stephen Bradley. Southland Hospital: Paul Tomlinson. Taranaki Hospital: John Doran. Tauranga Hospital: Hugh Lees. Timaru Hospital: Philip Morrison. University of Auckland: Jane Harding. Waikato Hospital: David Bourchier. Wanganui Hospital: Neil MacKenzie. Wellington Women's Hospital: Vaughan Richardson. Whakatane Hospital: Chris Moyes. Whangarei Hospital: Peter Jankowitz.

\section{Australia}

Centre for Perinatal Health Services Research, NSW: David Henderson-Smart*. Flinders Medical Centre, SA: Peter Marshall. John Hunter Hospital, NSW: Andrew Gill. King Edward Memorial Hospital for Women, WA: Ron Hagan. King George V Hospital, NSW: Nick Evans. Kirwan Hospital for Women, Qld: John Whitehall. Launceston General Hospital, Tas: Chris Bailey. Liverpool Health Service, NSW: Robert Guaran. Mater Mother's Hospital, Qld: David Tudehope. Maternity Alliance: Penny Waterson* (until 2000). Mercy Hospital for Women, Vic: Andrew Watkins. Monash Medical Centre, Vic: Kaye Bawden*, Andrew Ramsden (from 2000), Victor Yu. AIHW National Perinatal Statistics Unit, NSW: Paul Lancaster*. Nepean Hospital, NSW: Lyn Downe. Perinatal Research Centre, Qld: Paul Colditz. Princess Margaret Hospital for Children, WA: Ron Hagan, Paddy Pemberton (until 1999). Royal Children's Hospital, Vic: Neil Campbell (until 2000), Peter McDougall (from 2000). Royal Darwin Hospital, NT: Ingrid Bucens. Royal Hobart Hospital, Tas: Graham Bury. Royal Hospital for Women, NSW: Kei Lui. Royal North Shore Hospital, NSW: Jennifer Bowen. Royal Women's Hospital, Qld: David Cartwright*. Royal Women's Hospital, Vic: Colin Morley, Neil Roy. Sydney Children's Hospital, NSW: Barry Duffy. The Canberra Hospital, ACT: Graham Reynolds. The Children's Hospital at Westmead, NSW: Robert Halliday. Westmead Hospital, NSW: Marilyn Rochefort, William Tarnow-Mordi (from 2000). Women's \& Children's Hospital, SA: Ross Haslam. ANZNN Coordinator: Deborah Donoghue. ANZNN Project Officer: Anne Cust.

\section{Authors' affiliations}

A E Cust, D A Donoghue, Centre for Perinatal Health Services Research, University of Sydney, Sydney, NSW 2006, Australia

B A Darlow, Department of Paediatrics, Christchurch School of Medicine, Christchurch, New Zealand

\section{REFERENCES}

1 Evans DJ, Levene MI. Evidence of selection bias in preterm survival studies: a systematic review. Arch Dis Child Fetal Neonatal Ed 2001;84:F79-84.

2 Tommiska V, Heinonen K, lkonen S, et al. A national short-term follow-up study of extremely low birth weight infants born in Finland in 1996-1997. Pediatrics 2001;107:e2.

3 Finnstrom O, Olausson PO, Sedin G, et al. The Swedish national prospective study on extremely low birthweight (ELBW) infants. Incidence, mortality, morbidity and survival in relation to level of care. Acta Paediatr 1997:86:503-11.

4 Sutton L, Bajuk B. Population-based study of infants born at less than 28 weeks' gestation in New South Wales, Australia, in 1992-3. New South Wales Neonatal Intensive Care Unit Study Group. Paediatr Perinat Epidemiol 1999;13:288-301.

5 Wood NS, Marlow N, Costeloe K, et al. Neurologic and developmental disability after extremely preterm birth. N Engl J Med 2000;343:37884.

6 Hagan R, Benninger $H$, Chiffings $D$, et al. Very preterm birth: a regional study. Part 2. The very preterm infant. Br J Obstet Gynaecol $1996 ; 103: 239-45$

7 The Victorian Infant Collaborative Study Group. Outcome at 2 years of children 23-27 weeks' gestation born in Victoria in 1991-92. J Paediatr Child Health 1997;33:161-5.
8 Cartlidge PH, Stewart JH. Survival of very low birthweight and very preterm infants in a geographically defined population. Acta Paediatr 1997;86:105-10.

9 Lee SK, McMillan DD, Ohlsson A, et al. Variations in Practice and Outcomes in the Canadian NICU Network: 1996-1997. Pediatrics 2000; 106:1070-9.

10 Lemons JA, Baver CR, Oh W, et al. Very low birth weight outcomes of the National Institute of Child Health and Human Development Neonatal Research Network, January 1995 through December 1996. Pediatrics 2001;107:e 1

11 Darlow BA. Incidence of retinopathy of prematurity in New Zealand. Arch Dis Child 1988;63:1083-6.

12 Darlow BA, Horwood L. Chronic lung disease in very low birthweigh infants: a prospective population-based study. J Paediatr Child Health 1992;28:301-5.

13 Darlow BA, Clemett RS, Horwood L, et al. Prospective study of New Zealand infants with birth weight less than $1500 \mathrm{~g}$ and screened for retinopathy of prematurity: visual outcome at age $7-8$ years. $\mathrm{Br} J$ Ophthalmol 1997;81:935-40.

14 Darlow BA, Horwood L, Mogridge N, et al. Prospective study of New Zealand very low birthweight infants: outcome at 7-8 years. J Paediatr Child Health 1997:33:47-51.

15 Darlow BA, Horwood L, Mogridge N, et al. Survival and disability at $7-8$ years of age in New Zealand infants less than 28 weeks gestation. NZ Med J 1998;111:264-7

16 Horwood LJ, Mogridge N, Darlow BA. Cognitive, educational, and behavioural outcomes at 7 to 8 years in a national very low birthweight cohort. Arch Dis Child Fetal Neonatal Ed 1998;79:F12-20.

17 Sutton L, Bajuk B, Duffy B, et al. Short-term outcome of mechanically ventilated infants weighing more than $2499 \mathrm{~g}$ at birth: a population based study. J Paediatr Child Health 1993;29:418-23.

18 Horbar JD, Lucey JF. Evaluation of neonatal intensive care technologies. Future Child. 1995;5:139-61.

19 Horbar JD, Rogowski J, Plsek PE, et al. Collaborative quality improvement for neonatal intensive care. Pediatrics 2001;107:14-22.

20 Statistics New Zealand. Te Tari Tatau. Demographic trends 2000. http://www.stats.govt.nz/; 2001

21 Darlow BA, Cust AE, Donoghue DA. Improved outcomes for very low birthweight infants: evidence from New Zealand national population based data. Arch Dis Child Fetal Neonatal Ed 2003;88:

22 National Health and Medical Research Council. Clinical practice guidelines for care around preterm birth. Canberra: Australian Government Publishing Service, 1997

23 Donoghue DA, Cust AE. Report of the Australian and New Zealand Neonatal Network 1999. Sydney:ANZNN, 2001.

24 Donoghue DA, Cust AE. Australian and New Zealand Neonatal Network 1998. Sydney: AlHW National Perinatal Statistics Unit: Neonatal Network Series No 4, 2000.

25 World Health Organization. International classification of diseases, 9th revision. Geneva: WHO, 1975.

26 Isaacs D, CP Barfield, K Grimwood, et al. Systemic bacterial and fungal infections in infants in Australian neonatal units. Med J Aust 1995; 162:198-201.

27 Lawrence G, Tudehope D, Baumann K, et al. Enteral human lgG for prevention of necrotising enterocolitis: a placebo-controlled, randomised trial. Lancet 2001:357:2090-4.

28 International Committee for the Classification of Retinopathy of Prematurity. An international classification of retinopathy of prematurity. Pediatrics 1984;74:127-33.

29 Papile LA, Burstein J, Burstein R, et al. Incidence and evolution of subependymal and intraventricular hemorrhage: a study of infants with birth weights less than 1,500 gm. J Pediatr 1978;92:529-34.

30 Statistics New Zealand. Te Tari Tatau. Vital statistics: births. http://www.stats.govt.nz/; 2000.

31 Thompson JM, Mitchell EA, Borman B. Sex specific birthweight percentiles by gestational age for New Zealand. NZ Med J 1994;107:1-3.

32 Darlow BA, Clemett RS. Retinopathy of prematurity: screening and optimal use of the ophthalmologist's time. Aust N Z J Ophthalmol 1990;18:41-6

33 The Victorian Infant Collaborative Study Group. Changing outcome for infants of birth-weight 500-999 g born outside level 3 centres in Victoria. Aust N Z J Obstet Gynaecol 1997;37:253-7.

34 Harding JE, Morton SM. Adverse effects of neonatal transport between level III centres. J Paediatr Child Health 1993:29:146-9.

35 Malpas TJ, Meates J, Horwood J, et al. How safe is antenatal transfer between level 3 units? Aust N Z J Obstet Gynaecol 1997;37:258-60.

36 Bowman E, Doyle LW, Murton L, et al. Increased mortality of preterm infants transferred between tertiary perinatal centres. $B M$ 1988;297: 1098-100.

37 Berg CJ, Druschel CM, McCarthy BJ, et al. Neonatal mortality in normal birth weight babies: does the level of hospital care make a difference? Am J Obstet Gynecol 1989;161:86-91

38 Crowley P. Prophylactic corticosteroids for preterm birth (Cochrane Review). In: The Cochrane Library. Oxford: Update Software, 2001 :issue

39 Liggins GC, Howie RN. A controlled trial of antepartum glucocorticoid treatment for prevention of the respiratory distress syndrome in premature infants. Pediatrics 1972;50:515-25.

40 Egreteau L, Pauchard J-Y, Semama DS, et al. Chronic oxygen dependency in infants born at less than 32 weeks' gestation: incidence and risk factors. Pediatrics $2001 ; 108: \mathrm{e} 26-30$. 
41 Soll RF. Natural surfactant extract versus synthetic surfactant for neonatal respiratory distress syndrome (Cochrane Review). In: The Cochrane Library. Oxford: Update Software, 2001 : issue 4.

42 Wilson A, Gardner MN, Armstrong MA, et al. Neonatal assisted ventilation: predictors, frequency, and duration in a mature managed care organization. Pediatrics 2000;105:822-30.

43 Manktelow BN, Draper ES, Annamalai S, et al. Factors affecting the incidence of chronic lung disease of prematurity in 1987, 1992, and 1997. Arch Dis Child Fetal Neonatal Ed 2001;85:F33-5.

44 Copper RL, Goldenberg RL, Creasy RK, et al. A multicenter study of preterm birth weight and gestational age-specific neonatal mortality. Am J Obstet Gynecol 1993; 168:78-84.

45 Bahado-Singh RO, Dashe J, Deren O, et al. Prenatal prediction of neonatal outcome in the extremely low-birth-weight infant. Am J Obstet Gynecol 1998;178:462-8.

46 Tin W, Wariyar U, Hey E, et al. Changing prognosis for babies of less than 28 weeks' gestation in the north of England between 1983 and 1994. BM 1997;314:107-11.

47 Allen MC, Donohue PK, Dusman AE. The limit of viability-neonatal outcome of infants born at 22 to 25 weeks' gestation. N Engl J Med 1993:329:1597-601.

48 Costeloe K, Hennessy E, Gibson AT, et al. The EPICure study: outcomes to discharge from hospital for infants born at the threshold of viability. Pediatrics 2000;106:659-71

49 Saigal S, Hoult LA, Streiner DL, et al. School difficulties at adolescence in a regional cohort of children who were extremely low birth weight. Pediatrics 2000;105:325-31.
50 Vohr BR, Wright LL, Dusick AM, et al. Neurodevelopmental and functional outcomes of extremely low birth weight infants in the National Institute of Child Health and Human Development Neonatal Research Network, 1993-1994. Pediatrics 2000;105:1216-26.

51 Doyle LW, for the Victorian Infant Collaborative Study Group. Outcome at 5 years of age of children 23 to 27 weeks' gestation: refining the prognosis. Pediatrics 2001;108:134-41.

52 Philips JB, Dickman HM, Resnick MB, et al. Characteristics, mortality, and outcome of higher-birth weight infants who require intensive care. Am J Obstet Gynecol 1984;149:875-9.

53 Vincent T, Bajuk B, Sutton L, et al. Study of antecedents and outcomes of severe morbidity in term neonates in New South Wales: a comparison of major disability at 3 years. The Royal Australasian College of Physicians Annual Scientific Meeting, May 2001, Sydney. Sydney: Royal Australasian College of Physicians:69.

54 Ludman L, Spitz L, Lansdown R. Developmental progress of newborns undergoing neonatal surgery. J Pediatr Surg 1990;25:469-71.

55 Ludman L, Spitz L, Lansdown R. Intellectual development at 3 years of age of children who underwent major neonatal surgery. J Pediatr Surg 1993;28:130-4.

56 Spitz L. Neonatal surgery. J R Coll Surg Edinb 1995;40:84-7.

57 Pollack MM, Koch MA, Bartel DA, et al. A comparison of neonatal mortality risk prediction models in very low birth weight infants. Pediatrics 2000; 105:1051-7

\section{Archimedes}

In order to give the best care to patients and families, paediatricians need to integrate the highest quality scientific evidence with clinical expertise and the opinions of the family. Archimedes is a bimonthly section in Archives which seeks to assist practising clinicians by providing "evidence based" answers to common questions which are not at the forefront of research but are at the core of practice.

The format of Archimedes may be familiar. A description of the clinical setting is followed by a structured clinical question and a brief report of the search. The best evidence available to answer the question is provided as a summary table (which is electronically linked to more detailed appraisals). To pull the information together, a commentary follows. Finally, to make it all much more accessible, a box provides the clinical bottom line.

This month the following topics have been published which may be of interest to neonatologists:

- Likelihood ratios

- Should we glue lip lacerations in children?

- Is nebulised tolazoline an effective treatment for persistent pulmonary hypertension (PPH) of the newborn?

- How good is clinical examination at detecting a significant patent ductus arteriosus in the preterm neonate?

Previous Archimedes questions can be found in the issues of Archives published in the Fetal and Neonatal edition months since September 2001. Readers wishing to submit their own questions - with best evidence answers-are encouraged to read the Instructions for Authors at http://www.archdischild.com. 